RAD Conference Proceedings, vol. 2, pp. 90-94, 2017

www.rad-proceedings.org

\title{
DETERMINING THE EFFECT OF ESTABLISHMENT OF 4G SYSTEMS ON ELECTROMAGNETIC RADIATION LEVELS IN A PILOT DISTRICT
}

\author{
Çetin Kurnaz ${ }^{*}$, Doğan Yıldız, Serap Karagöl \\ Ondokuz Mayıs University, Engineering Faculty, \\ Department of Electrical and Electronics Engineering, Samsun, Turkey
}

\begin{abstract}
The level of radiofrequency electromagnetic fields (RF-EMF) exposure increases day by day as a natural consequence of technological development. In recent years, the increasing use of cellular systems due to technological developments in wireless communication systems has made it necessary to measure and evaluate RF-EMF originating from base stations which are the basic structure of these systems. In Turkey, as in April 2016, fourth generation of wireless mobile communication technology $(4 G)$ has been introduced and additional base stations are continuing to be added to the system. In this study, RF-EMF measurements were taken at four different times in order to examine and evaluate the change of RF-EMF before and after $4 G$ in Atakum district which is one of the most crowded districts of Samsun, Turkey. Two of the measurements were taken before $4 G$ and the remaining measurements were taken after $4 G$. Each measurement was taken at different times of the day (morning, noon and evening). The measurements were collected from 46 different locations using PMM 8053 RF-EMF meter which measures RF-EMF in the broad band from $100 \mathrm{kHz}$ to $3 \mathrm{GHz}$. In the measurements, the maximum electric field strength $\left(E_{\max }\right)$ and the average electric field strength $\left(E_{\text {avg }}\right)$ were recorded. The highest values that have been noticed in these measurements were $9.45 \mathrm{~V} / \mathrm{m}$ and $17.53 \mathrm{~V} / \mathrm{m}$ for $E_{\text {avg }}$ and $E_{\max }$, respectively. According to the measurement results, a decrease of $45.95 \%$ was observed in the measurement values of the morning hours compared to the measurement values of the evening and noon hours. The average RF-EMF value after $4 G$ was introduced has increased by 30.95\% compared to before 4G. Apart from these measurements, 24-hour measurements were taken at a location where the highest value was observed and analyzed to observe the change of RF-EMFs during a day.
\end{abstract}

Key words: Electric field strength, electromagnetic (EM) radiation, EM measurement

DOI: $10.21175 /$ RadProc.2017.19

\section{INTRODUCTION}

Technological products/systems, such as highvoltage lines, FM and TV transmitters, cellular systems, Bluetooth, microwave ovens, Wi-Fi, etc., which facilitate human life and increase in usage intensity, act as electromagnetic fields (EMF) sources. In particular, the increasing use of wireless systems has led to a significant increase in man-made radiofrequency EMF (RF-EMF). Measuring and evaluating RF-EMF from base stations, which are the basic building blocks of cellular systems, is of great importance for human health. The increase in the number of users using cellular systems, the ability of each base station to serve a limited area, and the ability of users to access the system from everywhere and use more multimedia force the cellular system operators to build more base stations. In parallel with this increase in base stations, an increase in the level of RF-EMF is also observed. There were around 100,000 base stations in Turkey before $4 \mathrm{G}$, but with the establishment of $4 \mathrm{G}$ systems on April 1, 2016, the estimated number of base stations is around 130,000. Because there is a growing number of base stations being placed into crowded places; measuring, evaluating the levels of RF-EMF and controlling their compliance with standards/limit values has become more crucial than before. Therefore, detrimental effects of RF-EMF on human health have been the subject of many researches [1-10] in the last decade.

There are many organizations in the world that are examining the effects of RF-EMF on human health due to cellular systems and setting some standards in this regard. The International Commission on Non-Ionizing Radiation Protection (ICNIRP) is the most important of these organizations. The ICNIRP identifies the areas where the RF-EMF level is detrimental to the frequency range [11]. Each country has its own determined limits. The USA and some European countries use limits determined by the ICNIRP, while other European countries like Switzerland and Italy use $1 / 10$ of the ICNIRP's values as a limit. Turkey applies limits that are $75 \%$ of ICNIRP reference levels as endorsed by Information Technologies and Communications Authority (ICTA) [12]. Reference levels for general public exposure to time-varying electric field strength (E) for ICNIRP and ICTA are shown in Table 1. The limits are given for exposure averaged over a six-minute interval. There are

*ckurnaz@omu.edu.tr 
currently three mobile communication operators in Turkey and they use $2 \mathrm{G}$ (second generation), $3 \mathrm{G}$ (third generation) and $4 \mathrm{G}$ (fourth generation) systems. According to [12], the limits are $30.9(\mathrm{~V} / \mathrm{m})$ for 900 $\mathrm{MHz}$ base station, $43.7(\mathrm{~V} / \mathrm{m})$ for $1800 \mathrm{MHz}$ base station, $45.75(\mathrm{~V} / \mathrm{m})$ for $3 \mathrm{G}$ systems, which is 2100 $\mathrm{MHz}$, and also $45.75(\mathrm{~V} / \mathrm{m})$ for $2600 \mathrm{MHz}$ base station.

Table 1. Reference levels for general public exposure to timevarying electric field strengths for ICNIRP and ICTA

\begin{tabular}{|c|c|c|}
\hline \multirow{2}{*}{$\begin{array}{c}\text { Frequency } \\
\text { range (MHz) }\end{array}$} & \multicolumn{2}{|c|}{ Electric field strength (V/m) } \\
\cline { 2 - 3 } & ICNIRP & ICTA \\
\hline $0.010-0.15$ & 87 & 65.25 \\
\hline $0.15-1$ & 87 & 65.25 \\
\hline $1-10$ & $87 / \mathrm{f}^{1 / 2}$ & $65.25 / \mathrm{f}^{1 / 2}$ \\
\hline $10-400$ & 28 & 21 \\
\hline $400-2000$ & $1.375 \mathrm{f}^{1 / 2}$ & $1.03 \mathrm{f}^{1 / 2}$ \\
\hline $2000-60000$ & 61 & 45.75 \\
\hline \multicolumn{2}{|c|}{$\mathrm{f}$ is frequency in MHz } \\
\hline
\end{tabular}

\section{MEasurement of Electric Field Strength}

In order to determine the changes in $\mathrm{E}$ levels with the deployment of $4 \mathrm{G}, \mathrm{E}$ measurements were conducted using PMM 8053 EMF meter [13] in Atakum district at 46 different locations, considering the number of users, line of sight, and distance from a base station. A picture of one of the measurements is shown in Figure 1. The measurements were done at a height of about $1.5 \mathrm{~m}$ above the ground. Each measurement location which is separated by a distance of app. 100 meters is shown with a red circle in Figure 2.

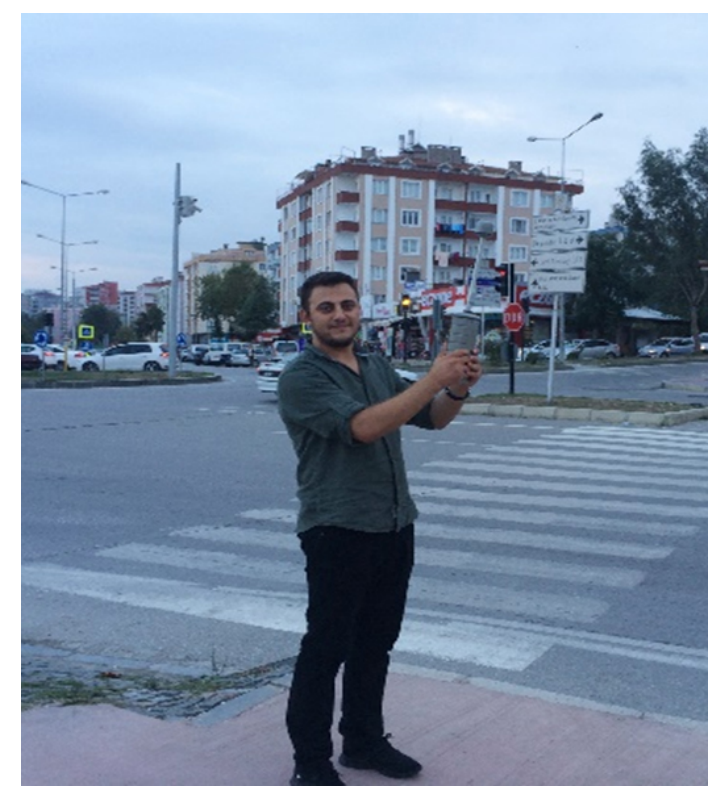

Figure 1. Taking measurement with PMM 8053 EMF meter

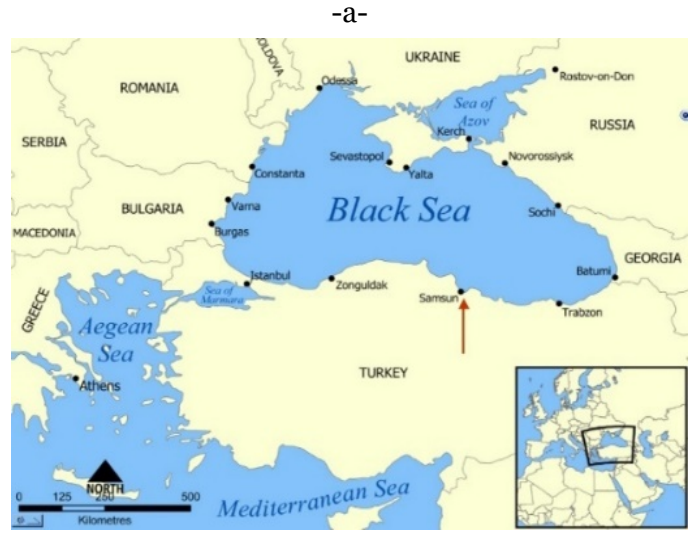

$-b-$

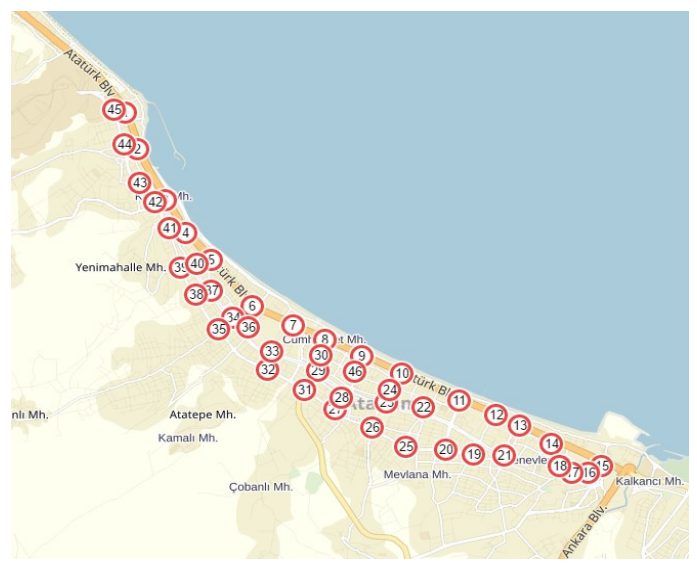

Figure 2. a) Location of Samsun, Turkey, b) Measurement locations in Atakum district

In this study, $\mathrm{E}$ measurements were taken at four different times in order to examine and evaluate the change of $\mathrm{E}$ before and after $4 \mathrm{G}$ in Atakum district, which is one of the most crowded districts of Samsun, Turkey. Total $\mathrm{E}$ in the band between $100 \mathrm{kHz}-3 \mathrm{GHz}$ was measured with PMM-8053 with EP-330 isotropic electric field probe [13] twice in August 2015, named M1 and M2, and in December 2016, named M3 and M4, respectively. Two of the measurements were taken before $4 \mathrm{G}$ (August 2015) and the remaining measurements were taken after 4G (December 2016). Each measurement was taken at three different times of the day (morning, noon and evening). In each measurement, the maximum electric field strength $\left(E_{\max }\right)$ and the average electric field strength $\left(E_{\text {avg }}\right)$ were recorded. Based on the international standards and ordinances released by ICNIRP and ICTA, the duration of each measurement was six minutes.

\section{Measurement Results}

In the first stage of the study, the maximum $\mathrm{E}$ $\left(\mathrm{E}_{\max }\right)$ and the average $\mathrm{E}\left(\mathrm{E}_{\mathrm{avg}}\right)$ were measured at 46 different locations and are given in Figure 3.a. and Figure 3.b respectively. In Figure 3, the $\mathrm{x}$ axis indicates the total of 12 measurement times (four different days, each day at three different times). The first measurement time (M1) represents the morning of the 
first measurement day, while the second (M2) and third (M3) measurement time represent the noon and evening of the first measurement day. Similarly, M4, M5, M6; M7, M8, M9; M10, M11, M12 are measurement times of morning, noon and evening for the second day, third day and fourth day, respectively. M1, M2, M3, M4, M5, M6 indicate E measurement times for before $4 \mathrm{G}$, while others indicate the same after $4 \mathrm{G}$. The reasons of various $\mathrm{E}$ levels may be: the number of base stations in the measurement area, output powers of base stations, distances from the base stations, whether there is line of sight between the units or not, and the number of users. As seen from Figure $3 . \mathrm{a}$, the $\mathrm{E}_{\max }$ is $4.77 \mathrm{~V} / \mathrm{m}$ which is measured at the $26^{\text {th }}$ location (measurement time 5 ). The maximum $\mathrm{E}_{\text {avg }}$ is also obtained at the $26^{\text {th }}$ location (measurement time 8) as $3.20 \mathrm{~V} / \mathrm{m}$ accordingly (Figure $3 . \mathrm{b}$ ).
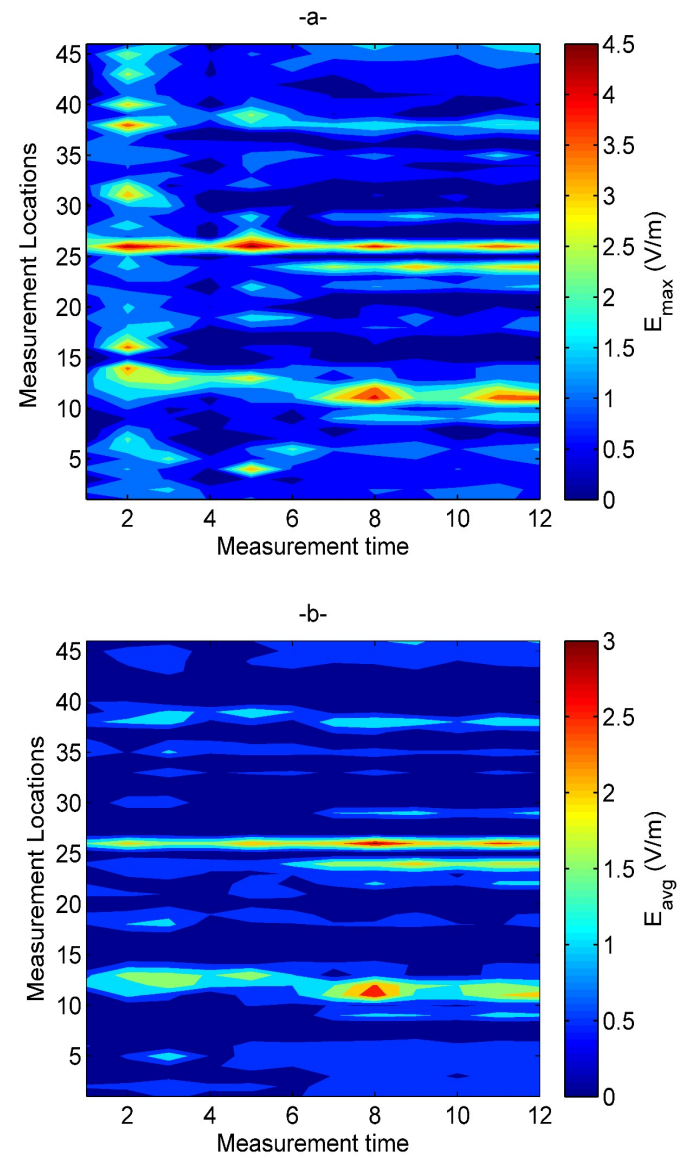

Figure 3. a) Maximum ( $\left.E_{\max }\right)$ b) Average ( $\left.E_{\text {avg }}\right)$ Es versus locations

The changes in the means of the $\mathrm{E}_{\mathrm{avg}} \mathrm{S}$ and $\mathrm{E}_{\max } \mathrm{S}$ for all of the measurements by locations are shown in Figure 4. It is seen from the figure that the maximum mean values of the $E_{\max }$ and $E_{\text {avg }}$ are reached at the $26^{\text {th }}$ location. The mean $\mathrm{E}_{\max }$ is $3.53 \mathrm{~V} / \mathrm{m}$, and mean $\mathrm{E}_{\mathrm{avg}}$ is $2.32 \mathrm{~V} / \mathrm{m}$ for this location.

Figure 5.a shows the maximum E values measured at the positions for all of the measurements at three different times of day (morning, noon and evening), while Figure 5.b shows the average $\mathrm{E}$ values. The mean
$\mathrm{E}_{\max }$ value is $1.26 \mathrm{~V} / \mathrm{m}$ for the noon, while it is 0.70 $\mathrm{V} / \mathrm{m}$ for the morning measurements. The mean $\mathrm{E}_{\mathrm{avg}}$ values are $0.54 \mathrm{~V} / \mathrm{m}$ for the noon and $0.37 \mathrm{~V} / \mathrm{m}$ for the morning measurements.

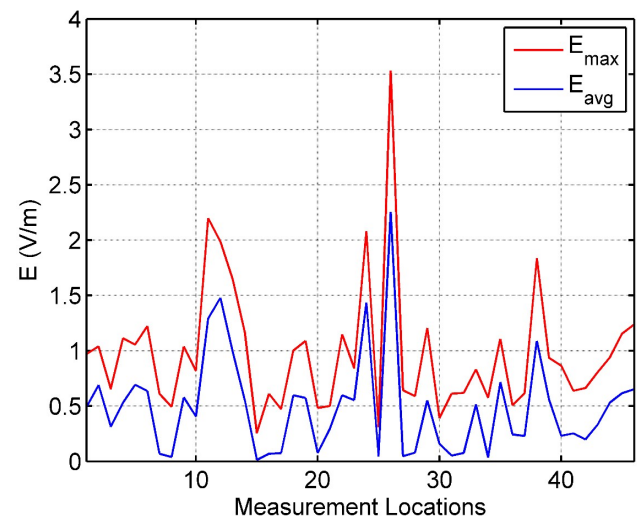

Figure 4. The mean values of $E_{\max }$ and $E_{\text {avg }}$ for twelve different measurement times

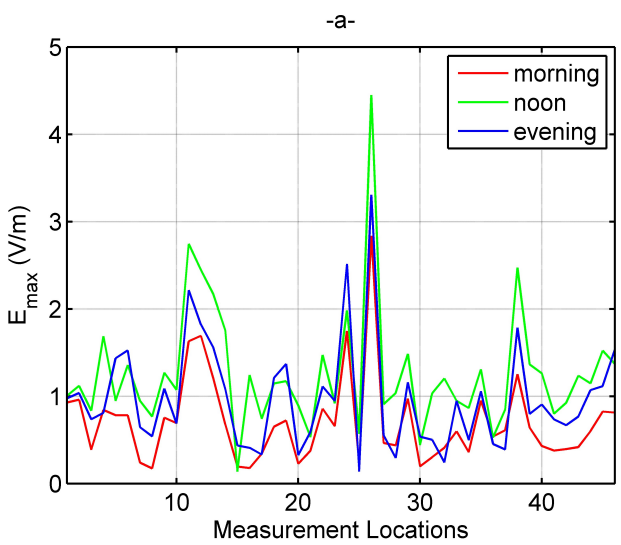

$-b-$

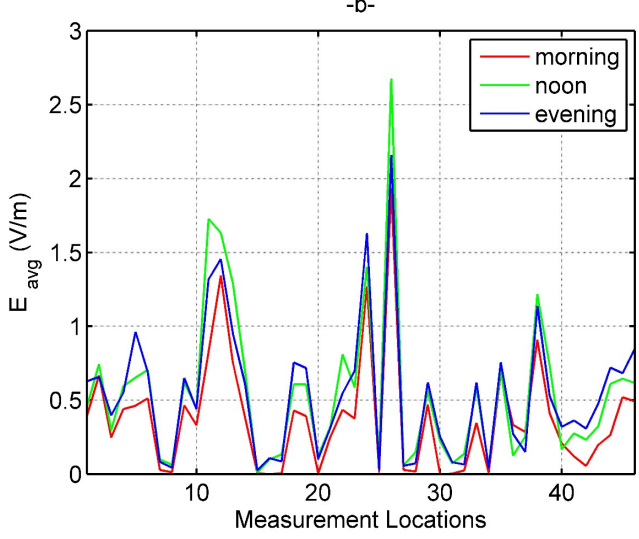

Figure 5. a) The $E_{\max } b$ ) the Eavg values for morning, noon, and evening

Figure 6.a shows the maximum E values obtained as a result of $\mathrm{E}$ measurements taken before and after $4 \mathrm{G}$. When the figure is examined, the $\mathrm{E}$ values obtained after $4 \mathrm{G}$ are generally higher than the $\mathrm{E}$ values obtained after $4 \mathrm{G}$. Figure 6.b shows the average E 
values obtained as a result of $\mathrm{E}$ measurements made before and after $4 \mathrm{G}$. Before $4 \mathrm{G}$, the mean of the $\mathrm{E}_{\max }$ was $1.03 \mathrm{~V} / \mathrm{m}$, and it decreased to $0.92 \mathrm{~V} / \mathrm{m}$ after $4 \mathrm{G}$. For the case of $E_{\text {avg, }}$, the corresponding values were 0.42 $\mathrm{V} / \mathrm{m}$ and $0.55 \mathrm{~V} / \mathrm{m}$. The average $\mathrm{E}$ value after $4 \mathrm{G}$ was introduced has increased by $30.95 \%$ compared to before $4 \mathrm{G}$.
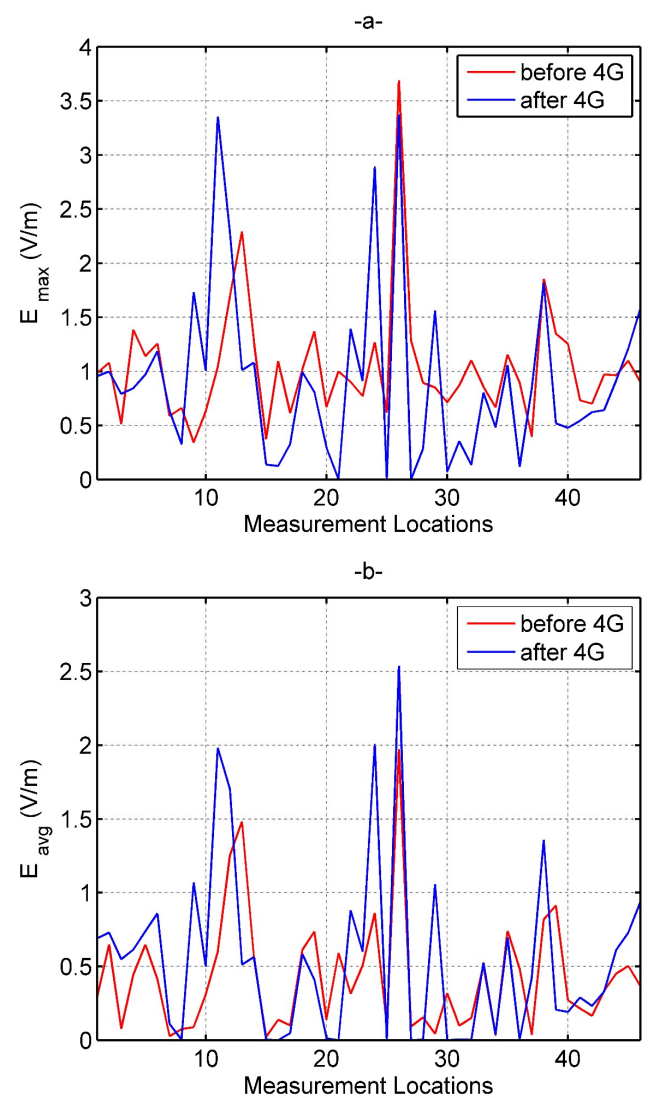

Figure 6. a) The maximum $\mathrm{E}$ values before and after $4 \mathrm{G}$ b) the average $\mathrm{E}$ values before and after $4 \mathrm{G}$

In order to have a better visualization of the changes in $\mathrm{E}$ levels, they are transferred on a map using MapInfo and the means of the $\mathrm{E}_{\mathrm{avg}} \mathrm{s}$ and $\mathrm{E}_{\max } \mathrm{s}$ for all of the measurements are shown in Figure 7.a. and Figure 7.b.

Measurements were taken to determine how the $\mathrm{E}$ values measured at location 26 change during a day and the results are given in Figure 8. A picture from the measurement location is given in Figure 9. This measurement is a 24 -hour measurement after $4 \mathrm{G}$. The measurement started at $6 \mathrm{pm}$ and continued until the next day. Figure 8 shows a great variation depending on the measurement hours. It is seen here that the number of users actively using the base station is the main factor influencing the $\mathrm{E}$. Low $\mathrm{E}$ values were measured between the hours of 05:00 - 07:00 at night, especially when using very high $\mathrm{E}$ values between 12:00 and 18:00. The highest measured $\mathrm{E}$ value was 17.53 $\mathrm{V} / \mathrm{m}$, while the 24-hour average was $9.4495 \mathrm{~V} / \mathrm{m}$. The standard deviation value is $2.0227 \mathrm{~V} / \mathrm{m}$ for this 24hour measurement.

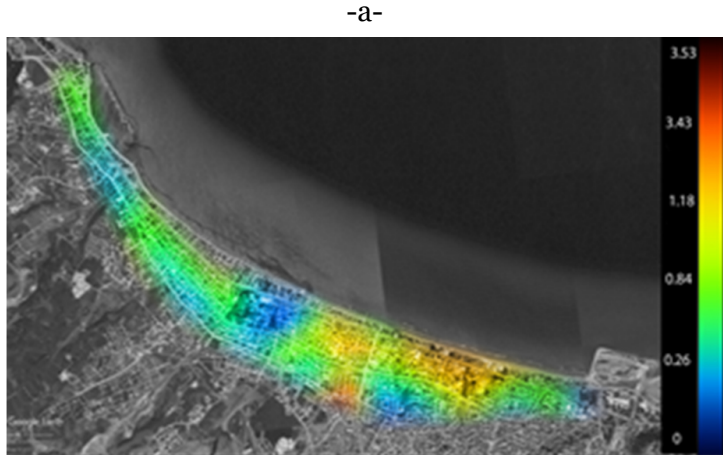

$-b-$

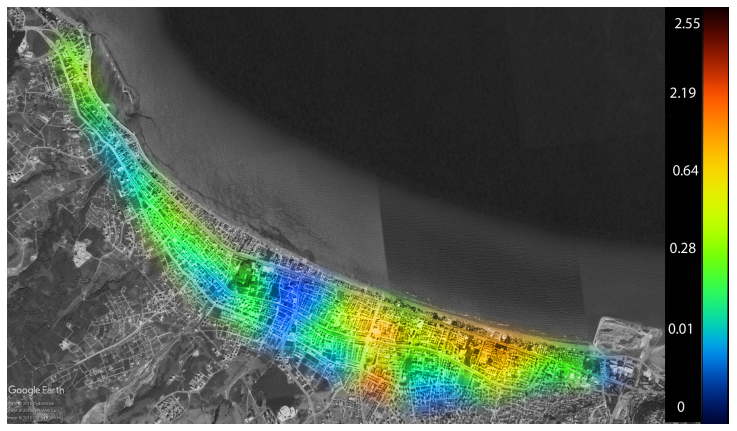

Figure 7. MapInfo picture of a) Emax b) Eavg after 4G

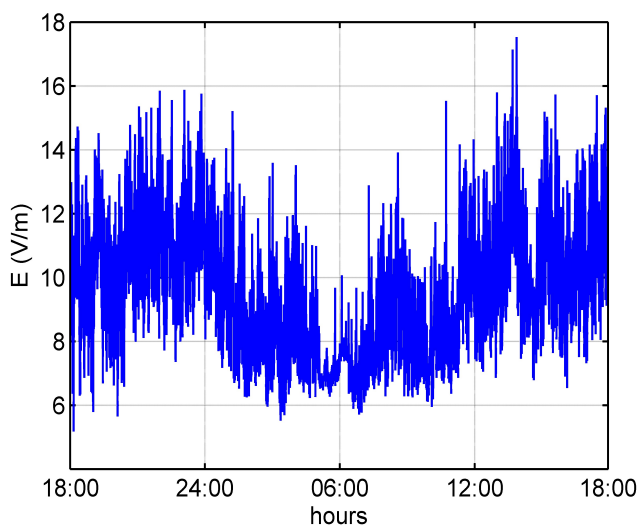

Figure 8. E levels during a day for location 26

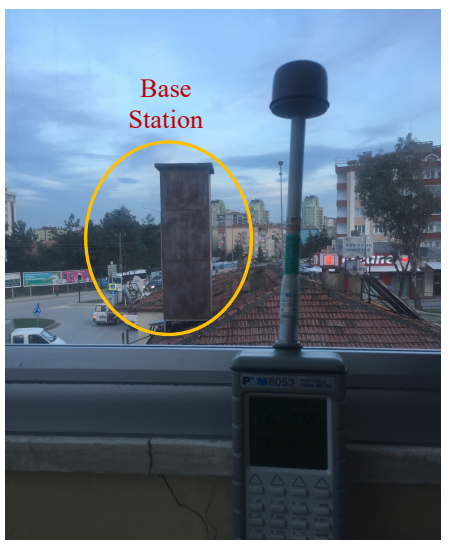

Figure 9. A picture of location 26 


\section{CONCLUSIONS}

In this study, RF-EMF measurements were taken at four different times in order to examine and evaluate the change of RF-EMF before and after $4 \mathrm{G}$ in Atakum district, which is one of the most crowded districts of Samsun, Turkey. Two of the measurements were taken before $4 \mathrm{G}$ and the remaining measurements were taken after 4G. Each measurement was taken at three different times of the day. When the results are examined, the measured RF-EMF values may vary depending on the measurement location and the measurement time. The highest measured electric field value is $17.53 \mathrm{~V} / \mathrm{m}$ and the highest average electric field value is $9.44 \mathrm{~V} / \mathrm{m}$. Even though the measured E levels are below the limits that are determined by ICNIRP and ICTA; they may be considered as high in some countries (e.g. Switzerland and Italy) where lower limits are applied. According to the measurement results, a decrease of $45.95 \%$ was observed in the measurement values of the morning hours compared to the measurement values of the evening and noon hours. The average RF-EMF value after $4 \mathrm{G}$ was introduced has increased by 30.95\% compared to before $4 \mathrm{G}$. Apart from these measurements, a 24-hour measurement was taken at a location where the highest value was observed and it was analyzed to observe the change of RF-EMFs during a day.

\section{REFERENCES}

1. C. Kurnaz, "An Empirical Modelling of Electromagnetic Pollution on an University Campus," The Applied Computational Electromagnetic Society Express Journal, vol. 1, no. 2, pp.76-79, Feb. 2016.

Retrieved from:

http://www.aces-

society.org/includes/downloadpaper.php?of=ACES

Express Journal February 2016 Paper $10 \& \mathrm{nf}=$ ej-16-2-10

Retrieved on: Jan. 9, 2017

2. B. K. Engiz, Ç. Kurnaz, "Long-Term Electromagnetic Field Measurement and Assessment for a Shopping Mall," Radiation Protection Dosimetry, Nov. 2016.

DOI: $10.1093 / \mathrm{rpd} / \mathrm{ncw} 343$

3. B. K. Gül, Ç. Kurnaz, B. K. Engiz, "Measurement and Evaluation of Electromagnetic Pollution in Ondokuz Mayss University Kurupelit Campus in Samsun, Turkey," in Proc. Third International Conference on Advances in Information Processing and Communication Technology, Rome, Italy, 2015, pp.80-84.

Retrieved from:

https://www.researchgate.net/publication/305387 736 Measurement and Evaluation of Electroma gnetic Pollution in Ondokuz Mayis University Kurupelit Campus in Samsun Turkey

Retrieved on: Jan. 27, 2017

4. A. Mousa, "Electromagnetic radiation measurements and safety issues of some cellular base stations in Nablus," Journal of Engineering
Science and Technology Review, vol. 4, no. 1, pp. 35-42, Feb. 2011.

Retrieved from:

http://www.jestr.org/downloads/volume4/fulltext 072011.pdf

Retrieved on: Jan. 27, 2017

5. O. Genç, M. Bayrak, E. Yaldız, "Analysis of the effects of GSM bands to the electromagnetic pollution in the RF spectrum," Prog. Electromagn. Res. PIER, vol. 101, pp. 17-32, 2010. DOI: 10.2528/PIERo9111004

6. S. Miclaus, P. Bechet, "Estimated and Measured values of the Radiofrequency Radiation Power Density around Cellular Base Stations," Rom. Journ. Phys., vol. 52, no. 3-4, pp. 429-440, 2007. Retrieved from:

http://www.nipne.ro/rjp/2007_52 34/0429 0441.pdf

Retrieved on: Jan. 7, 2017

7. L. Seyfi, "Measurement of electromagnetic radiation with respect to the hours and days of a week at $100 \mathrm{kHz}-3 \mathrm{GHz}$ frequency band in a Turkish dwelling," Measurement, vol. 46, no. 9, pp. 30023009, Nov. 2013. DOI: 10.1016/j.measurement.2013.06.021

8. P. Baltrenas, R. Buckus, "Measurements and analysis of the electromagnetic fields of mobile communication antennas," Measurement, vol. 46, no. 10, pp.3942-3949, Dec. 2013. DOI: 10.1016/j.measurement.2013.08.008

9. M. Koprivica, V. Slavkovic, N. Neskovic, A. Neskovic, "Statistical Analysis of Electromagnetic Radiation Measurements in the Vicinity of GSM/UMTS Base Station Installed on Buildings in Serbia," Radiation Protection Dosimetry, vol. 168, no. 4, pp. 489-502, Mar. 2016.

DOI: $10.1093 / \mathrm{rpd} / \mathrm{ncv} 372$ PMid: 26231558

10. T. Karadag, M. Yüceer, T. Abbasov, "A Large-Scale Measurement, Analysis And Modelling of Electromagnetic Radiation Levels in the Vicinity of GSM/UMTS Base Stations in an Urban Area," Radiation Protection Dosimetry, vol. 168, no. 1, pp. 1-14, Jan. 2016.

DOI: $10.1093 / \mathrm{rpd} / \mathrm{ncvoo} 8$

PMid: 25693600

11. International Commission on Non-Ionizing Radiation Protection, "Guidelines for Limiting Exposure to Time-Varying Electric, Magnetic, and Electromagnetic Fields (up to $300 \mathrm{GHz}$ ), Health Physics, vol. 74, no. 4, pp. 494-522, 1998.

Retrieved from:

http://www.icnirp.org/cms/upload/publications/I CNIRPemfgdl.pdf

Retrieved on: Jan. 25, 2017

12. Information and Communication Technologies Authority of Turkey. (Oct. 9, 2015). Law no. 29497 Ordinance change on By-Law on Determination, Control and Inspection of the Limit Values of Electromagnetic Field Force from The Electronic Communication Devices According to International Standards.

13. PMM 8053B Field Probes Catalog, Narda Safety Test Solutions, Savona, Italy.

Retrieved from:

www.pmm.eu/includes/sendfile.asp?nomep=Field Probes

Retrieved on: Feb. 14, 2017 